\title{
Mitral valve surgery: Right lateral minithoracotomy or sternotomy? A systematic review and meta-analysis
}

\author{
Simon H. Sündermann, MD, ${ }^{a}$ Juri Sromicki, MD, ${ }^{a}$ Héctor Rodriguez Cetina Biefer, MD,,${ }^{\mathrm{a}, \mathrm{b}}$ \\ Burkhardt Seifert, MD, PhD, ${ }^{\mathrm{c}}$ Tomas Holubec, MD, ${ }^{\mathrm{a}}$ Volkmar Falk, MD, PhD, ${ }^{\mathrm{a}}$ and Stephan Jacobs, $\mathrm{MD}^{\mathrm{a}}$
}

Objective: To update the current evidence on mitral valve surgery through a lateral minithoracotomy versus median sternotomy.

\begin{abstract}
Methods: A comprehensive literature research was performed for studies comparing mitral valve surgery through a right lateral minithoracotomy (MIVS) and median sternotomy in MEDLINE, EMBASE, Cochrane Central, CTSnet, and Google Scholar for the most recent literature up to April 2013. A systematic review and meta-analysis was performed on the studies found in the literature.

Results: More than 20,000 patients from 45 studies were included in this study. Stroke rate and all-cause mortality up to 30 days was similar in both groups. The length of stay in the intensive care unit, respirator dependence, and hospital stay were significantly shorter in the MIVS group. Furthermore, blood drainage volume and blood transfusions were decreased in the MIVS group. In contrast, cardiopulmonary bypass time, crossclamp time, and procedure time were longer in the MIVS group. Postoperative new atrial fibrillation was less in the MIVS group. More aortic dissections occurred in the MIVS group. The rates of reexploration and postoperative renal failure were similar in both groups.
\end{abstract}

Conclusions: MIVS and conventional mitral valve surgery have a similar perioperative outcome. Mitral valve surgery via a right lateral minithoracotomy seems to be favorable with regard to resource-related outcome. (J Thorac Cardiovasc Surg 2014;148:1989-95)

Supplemental material is available online.

Right lateral minithoracotomy has become the standard approach for mitral valve surgery in many centers and is considered to be minimally invasive (MIVS) access. There is still ongoing debate about the benefits of minimally invasive interventions. Several studies as well as 2 meta-analyses comparing conventional surgery (CS) and minimally invasive surgery are available in the literature. In the meta-analysis by Cheng and colleagues, ${ }^{1}$ a higher rate of stroke was found in the group of patients treated

\footnotetext{
From the Division of Cardiovascular Surgery, ${ }^{\mathrm{a}}$ University Hospital Zurich, Zurich, Switzerland; Division of Transplant Surgery and Transplantation Surgery Research Laboratory, ${ }^{\mathrm{b}}$ Brigham and Women's Hospital, Harvard Medical School, Boston, Mass; and Division of Biostatistics, ${ }^{\mathrm{c}}$ Institute of Social and Preventive Medicine, University of Zurich, Zurich, Switzerland.

Disclosures: Volkmar Falk reports consulting fees from Valtec and lecture fees from Edwards and Philips. All other authors have nothing to disclose with regard to commercial support.

Presented at The 2013 American Association for Thoracic Surgery Mitral Conclave, New York, New York, May 2, 2013.

Received for publication Aug 23, 2013; revisions received Jan 19, 2014; accepted for publication Jan 30, 2014; available ahead of print Feb 28, 2014.

Address for reprints: Simon H. Sündermann, MD, Raemistrasse 100, CH-8091

Zürich, Switzerland (E-mail: simon.suendermann@usz.ch).

0022-5223/\$36.00

Copyright (c) 2014 by The American Association for Thoracic Surgery

http://dx.doi.org/10.1016/j.jtcvs.2014.01.046
}

with MIVS. This study contradicts the meta-analysis presented by Modi and colleagues. ${ }^{2}$ Because of these conflicting results and the recent literature now available, we performed a systematic review and meta-analysis to update the current evidence.

The objective of this systematic review and meta-analysis was to determine the outcome of patients treated either minimally invasively through a right lateral minithoracotomy or conventionally via a median sternotomy. Mortality and neurologic outcome were the main interest. In addition, procedure- and resource-related outcomes were assessed.

\section{METHODS}

A systematic review and meta-analysis of comparative studies was performed in accordance with the methodological recommendations by PRISMA (Preferred Reporting Items for Systematic Reviews) and MOOSE (Meta-Analysis of Observational Studies in Epidemiology) for randomized and observational studies. ${ }^{3,4}$ Outcomes, search strategies, inclusion criteria, and statistical analysis were predefined before the literature research.

\section{End Points}

End points were defined as 30-day mortality, stroke, postoperative myocardial infarction, new onset of atrial fibrillation, new renal insufficiency, perioperative aortic dissection, rethoracotomy for bleeding, need for blood transfusion, blood drainage volume, procedure time, crossclamp time, cardiopulmonary bypass (CPB) time, length of hospital stay, length of intensive care unit (ICU) stay, length of respirator dependence, and costs.

\section{Literature Research}

A comprehensive literature search was performed in MEDLINE, EMBASE, Cochrane CENTRAL, CTSnet, and Google Scholar from the 


$$
\begin{aligned}
& \text { Abbreviations and Acronyms } \\
& \begin{aligned}
\mathrm{CI} & =\text { confidence intervals } \\
\mathrm{CPB} & =\text { cardiopulmonary bypass } \\
\mathrm{CS} & =\text { conventional surgery } \\
\mathrm{ICU} & =\text { intensive care unit } \\
\mathrm{MIVS} & =\text { minimally invasive surgery } \\
\mathrm{RR} & =\text { risk ratio } \\
\mathrm{WMD} & =\text { weighted mean difference }
\end{aligned}
\end{aligned}
$$

earliest possible date until April 2013. Search terms were "mitral valve surgery," "robotic surgery," "port access surgery," "thoracoscopic surgery," "minimally invasive surgery," "sternotomy," and variants and combinations of these keywords. The search was performed without any limits with regard to publication date, study design, or language. References from reviews were for manually searched for relevant articles. Experts were asked for further literature or unpublished data.

\section{Inclusion Criteria}

Randomized or nonrandomized studies comparing mitral valve surgery (repair or replacement) via a right lateral minithoracotomy (with or without camera support, with or without robotic support) versus sternotomy (through a complete median sternotomy) were included.

\section{Exclusion Criteria}

Studies including mainly redo surgical procedures were excluded.

The cause of the mitral valve disease was not taken into consideration for inclusion or exclusion of the studies.

\section{Data Analysis}

For baseline characteristics, weighted mean differences or risk ratios were calculated to describe differences between the groups. When significant heterogeneity was seen in the Q statistics $\left(\mathrm{I}^{2}>60 \%\right)$, the random effects model was used. Otherwise, the fixed effects model was used. In the meta-analysis, risk ratios (RRs) and 95\% confidence intervals (CIs) were calculated for end points with discrete data. For continuous data, weighted mean differences (WMD) and 95\% CIs were calculated. The $\mathrm{Q}$ statistic was used to calculate heterogeneity $\left(\mathrm{I}^{2}\right)$. RR and WMD were calculated using the random effects model when significant heterogeneity was present $\left(I^{2}>60 \%\right)$. Statistical significance was defined as $P<.05$ or a confidence interval that excluded the value 1.00 for RR and 0 for WMD. The meta package in $\mathrm{R}$ was used for the meta-analysis as described by Guido Schwarzer in 2012 (meta: Meta-Analysis with R. R package version 2.1-1; available at: http://cran.r-project.org/web/packages/meta/meta.pdf).

\section{RESULTS}

\section{Study Identification}

The initial search in the different databases resulted in more than 3400 records. Almost 3000 records were excluded immediately because of description of irrelevant data. After exclusion of these records, 504 papers were retrieved for full review. Forty-one articles included studies that met the inclusion criteria for the comparison of MIVS versus $\mathrm{CS}^{5-45}$ (Figure 1). In 4 articles, ${ }^{11,26,35,42}$ different studies within the same article were identified, resulting in a total of 45 studies. Three studies ${ }^{9,10,40}$ were prospectively randomized; the rest of the studies were nonrandomized and mainly retrospective. Six of these were propensity score matched. ${ }^{14,17,21,22,28,38}$ The studies were published between 1997 and 2013 mainly from the United States (22), followed by Germany (6), China (2), France (2), Slovenia (2), and 1 study each from Egypt, Serbia, Brazil, Israel Austria, India, and Italy. Crossclamping was predominantly performed; endoaortic balloon occlusion was performed in only 19 studies. $^{5,6,9,15,16,18-20,26,28,29,32,33,35,36,3,42}$ In 16 studies, direct transthoracic crossclamping was predominantly used. $^{7,8,10-12,21-24,30,34,40,41,45}$ In the rest of the studies $(\mathrm{n}=11)$, both modalities were used in the same proportion or it was not clearly stated which technique was mainly used.

\section{Baseline Characteristics}

The baseline characteristics are summarized in Table 1. A total of 20,342 patients were represented in the studies. MIVS was performed in 11,088 patients and CS was performed in 9254 patients. Patients in the MIVS group were younger on average by 1.7 years $(57.3 \pm 9.3$ years vs $58.6 \pm 9.6$ years). Body mass index was lower in the MIVS group on average by $0.54 \mathrm{~kg} / \mathrm{m}^{2}\left(25.7 \pm 2.8 \mathrm{~kg} / \mathrm{m}^{2}\right.$ vs $26 \pm 2.5 \mathrm{~kg} / \mathrm{m}^{2}$ ). Fewer patients had renal failure (RR, 0.23 ) in the MIVS group. Left ventricular ejection fraction was better in the MIVS group on average by $1.3 \%$ (55.8\% $\pm 7.3 \%$ vs $54.9 \% \pm 8.1 \%$ ). Other risk factors did not differ significantly. More patients had a mitral valve repair in the MIVS group ( $82 \%$ vs $75 \%$; RR, 1.2 ; $(95 \%$ CI, $1.0-1.5)$ in the random effects model $\left.\left(\mathrm{I}^{2}=95 \%\right) ; P=.04\right)$.

\section{All-Cause Mortality}

All-cause mortality was described in 29 studies with a total of 18,019 patients. $7,9,10,12-14,16,17,19-25,27,28,30,32,34,35,37$, $38,40,41,43-45$ All-cause mortality up to 30 days was $1.6 \%$ and did not differ significantly between patients treated with MIVS or CS (1.4\% vs $1.7 \%$, respectively). There was no significant heterogeneity among the studies for this outcome $\left(\mathrm{I}^{2}=36 \%\right)$, thus the fixed effects model was used (RR, 0.79; 95\% CI, 0.63-0.99; $P=.04)$. The linear regression test showed no asymmetry in a funnel plot $(P>.2)$. The results are illustrated in Figure 2.

\section{Stroke}

Total stroke rate was $1.7 \%(\mathrm{n}=18$ studies $)$ in 14390 patients. $7,11,14,17,19,21-24,27,28,30,32,38,40,41$ There was no significant difference with regard to stroke rate between groups $(1.7 \%$ in the MIVS group vs $1.6 \%$ in the CS group). There was significant heterogeneity among the studies $\left(\mathrm{I}^{2}=60 \% ; P=.012\right)$. The risk ratio in the random effects model was 0.68 (95\% CI, 0.39-1.20). The linear regression test of funnel plot asymmetry showed significant asymmetry $(P=.012)$ (Figure 3$)$. 


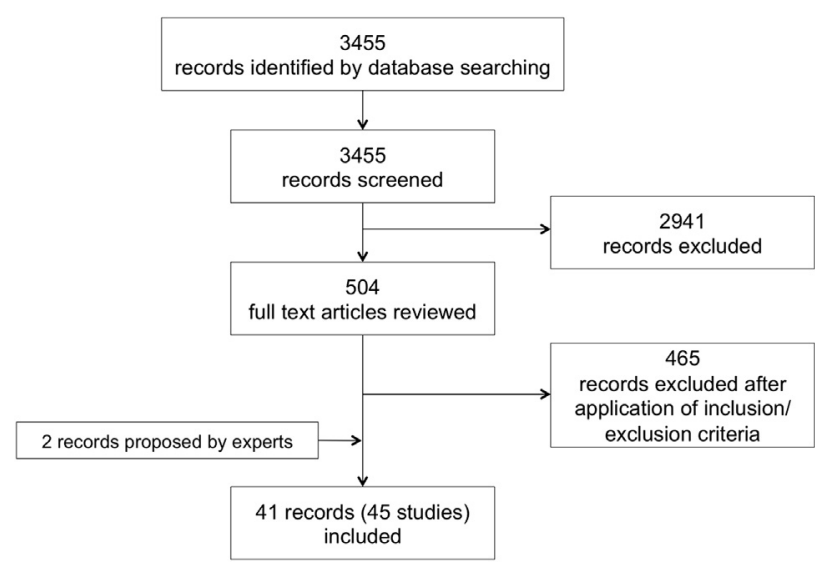

FIGURE 1. Study flowchart.

A subanalysis was performed for those studies in which mainly endoaortic balloon occlusion or transthoracic crossclamping was used. $5,6,9,15,16,18-20,26,28,29,32,33,35,36,38,42$ There was a clear difference between the groups. In the analysis of studies in which a transthoracic crossclamp was used for both groups, the results showed a decreased stroke rate in patients with minimally invasive procedures $\left(\mathrm{I}^{2}=0 \%\right.$; fixed effects model RR, $0.39 ; 95 \% \mathrm{CI}$, $0.24-0.61 ; P<.001)$. In the studies in which endoaortic balloon occlusion was used in the MIVS group, the results were in favor of conventional sternotomy $\left(\mathrm{I}^{2}=0 \%\right.$; fixed effect model $\mathrm{RR}, 1.89 ; 95 \% \mathrm{CI}$, $0.87-4.14 ; P>.2)$.

\section{Other End Points}

All other end points are summarized in Table 2. Procedure time (Figure E1), CPB time (Figure E2), and crossclamp time (Figure E3) were longer in the MIVS group. Blood drainage volume (Figure E4) and need for blood transfusion (Figure E5) was reduced in the MIVS group as well as length of ICU stay (Figure E6), length of respirator dependence (Figure E7), and length of hospital stay (Figure E8). The rate of rethoracotomies (Figure E9) was similar in both groups as well as the rate of new onset of atrial fibrillation (Figure E10) and new postoperative renal failure (Figure E11). Aortic dissection was recorded for only 4 patients in the MIVS group. Total costs were less in the MIVS group.

\section{DISCUSSION}

In this systematic review and meta-analysis, we aimed to include the current literature comparing MIVS performed via a right lateral thoracotomy and CS performed via a median sternotomy of the mitral valve to determine differences in the outcome.

The main differences between the procedures were found for procedure- and resource-related outcomes. In the discussion about the optimal access for mitral valve surgery, these outcomes are often used to argue for or against one or the other procedure. In this context, we assessed CPB time, crossclamp time, procedure time, length of hospital stay, ICU stay as well as other factors. In line with previous reports, we found that $\mathrm{CPB}$ time, crossclamp time, and procedure time were increased in the MIVS group. In contrast, length of ICU stay, respirator dependence, and length of hospital stay were significantly reduced. Few studies calculated and compared costs for both procedures and it seems that minimally invasive procedures cumulate fewer costs than conventional procedures. However, because of the low number of studies on this issue, a general assertion cannot be made. These findings are also in accordance with previous meta-analyses. ${ }^{1,2}$

For perioperative outcome, 30-day mortality and stroke rate were the main interest. This was mainly due to the study presented by Cheng and colleagues, ${ }^{1}$ in which the reported stroke rate was alarming high in the MIVS group.

TABLE 1. Baseline characteristics of the patients

\begin{tabular}{lcccccc}
\hline & $\mathbf{n}(\mathbf{N})$ & MIVS & CS & WMD or RR (95\% CI) & $\boldsymbol{P}$ & $\mathbf{I}^{2}(\%)$ \\
\hline Age, y \pm SD & $33(10,454)$ & $57.0 \pm 9.6$ & $58.4 \pm 9.8$ & $-1.7(-2.3$ to -1.1$)$ & $<.001$ & 95 \\
Female, \% & $31(15,717)$ & 49 & 47 & $1.0(0.9$ to 1.1$)$ & $>.2$ & 82 \\
LVEF, \% \pm SD & $20(14,247)$ & $55.8 \pm 7.3$ & $54.9 \pm 8.1$ & $1.3(-0.3$ to 2.2$)$ & .01 & 99 \\
Mitral stenosis, \% & $11(1803)$ & 15 & 16 & $0.98(0.80$ to 1.20$)$ & $>.2$ & 0 \\
Mitral regurgitation (degenerative), \% & $11(1950)$ & 82 & 79 & $1.02(0.99$ to 1.05$)$ & $>.2$ & 62 \\
BMI, kg/m ${ }^{2} \pm$ SD & $6(2702)$ & $25.7 \pm 2.8$ & $26 \pm 2.5$ & $-0.54(-0.89$ to -0.19$)$ & .003 & 99 \\
Diabetes, \% & $13(12,466)$ & 8 & 8 & $0.95(0.69$ to 1.32$)$ & $>.2$ & 64 \\
CVD, \% & $9(12,625)$ & 9 & 9 & $0.66(0.41$ to 1.1$)$ & .08 & 90 \\
HT, \% & $7(11,328)$ & 57 & 50 & $1.00(0.97$ to 1.04$)$ & $>.2$ & 0 \\
AFIB, \% & $9(9765)$ & 21 & 22 & $0.97(0.90$ to 1.05$)$ & $>.2$ & 30 \\
Renal insufficiency, \% & $3(1373)$ & 0.6 & 2.8 & $0.23(0.08$ to 0.63$)$ & .005 & 0 \\
COPD, \% & $7(10,718)$ & 10 & 11 & $0.90(0.80$ to 1.00$)$ & .07 & 47 \\
\hline
\end{tabular}

$n$, Number of studies; $N$, total number of patients; MIVS, minimally invasive surgery, right lateral minithoracotomy; $C S$, conventional surgery, midline sternotomy; $W M D$, weighted mean difference; $R R$, risk ratio; $I^{2}$, test of heterogeneity (when $\mathrm{I}^{2}$ was $>60 \%$, the random effects model was used, otherwise the fixed effects model was used); $C I$, confidence interval; $S D$, standard deviation; $L V E F$, left ventricular ejection fraction; $B M I$, body mass index; $C V D$, cerebrovascular disease; $H T$, arterial hypertension; $A F I B$, atrial fibrillation; $C O P D$, chronic obstructive pulmonary disease. 

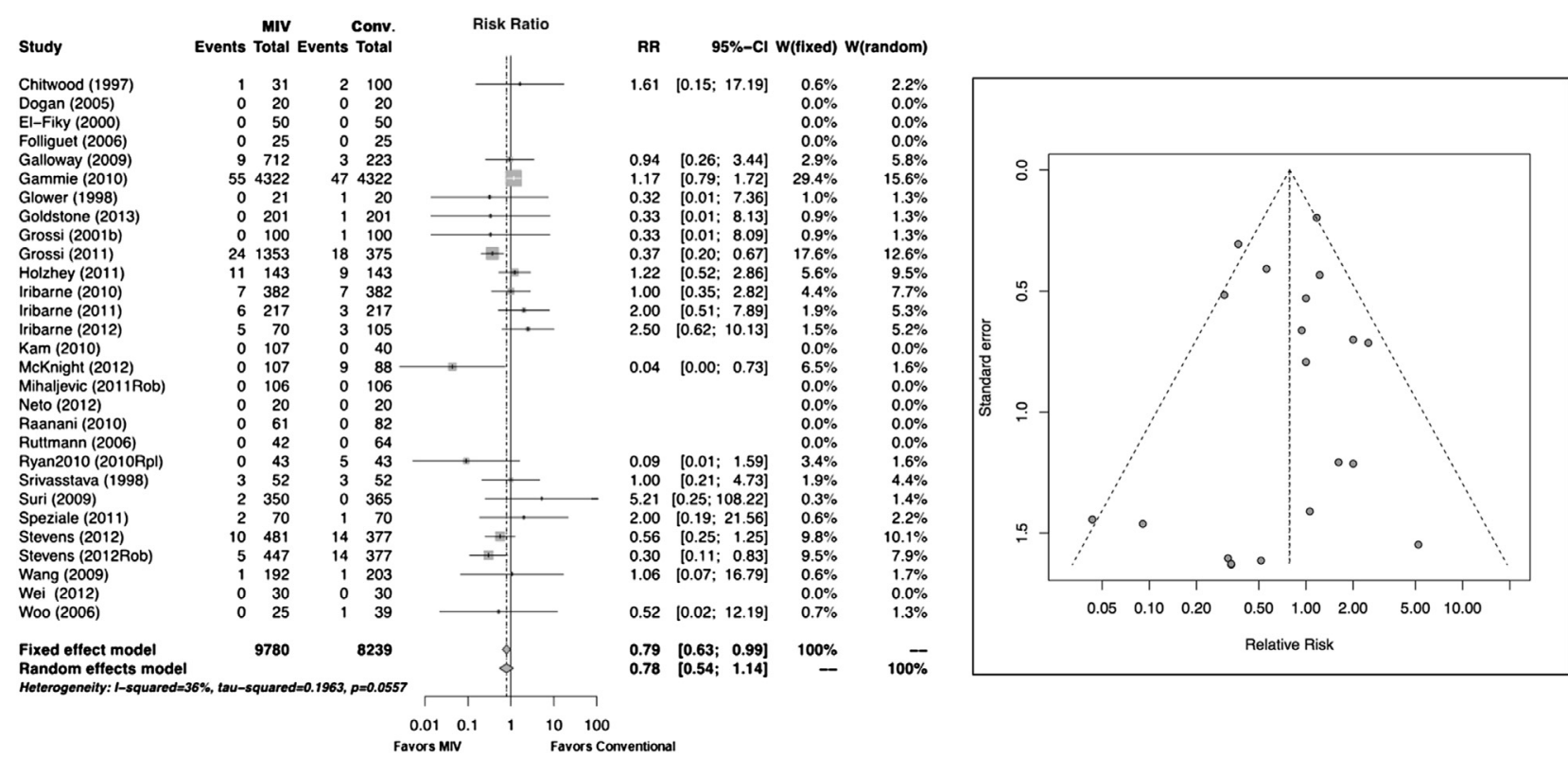

FIGURE 2. Forest and funnel plots for all-cause mortality up to 30 days. $M I V$, Minimally invasive; Conv, conventional; $R R$, risk ratio; $C I$, confidence interval; $W$, weight.

Mortality did not differ significantly between both groups, which is in line with 2 previously published meta-analyses. Cheng and colleagues ${ }^{1}$ raised the issue that the large, propensity-matched analysis from Gammie and colleagues ${ }^{14}$ shows a significant increase in the composite end point of major hospital morbidity (defined as the need for reoperation, deep sternal wound infection, stroke, renal failure, or prolonged ventilation or both) and mortality in the MIVS group leading to potential concern about the safety of minimally invasive procedures. Unfortunately, in newer propensitymatched or prospective studies since the meta-analysis from Cheng and colleagues, ${ }^{1}$ this combined end point is not assessed. One prospective, randomized controlled trial and 1 propensity-matched analysis, both from $2011,{ }^{21,40}$ show higher mortality in the MIVS group. The event rate is low in both studies. The single end points, which were combined in the composite end point in the publication by Gammie and colleagues, ${ }^{14}$ all show results in favor of minimally invasive procedures in newer publications. One exception is the rate of reoperation for bleeding in the publication by Goldstone and colleagues ${ }^{17}$ from 2013 showing a 5-fold higher rate of rethoracotomies in the MIVS group $(2.5 \%$ vs $0.5 \%$ ); however the reasons are not explained. The $30-$ day mortality within all studies is low at $1.5 \%$.

Stroke rate was low and similar in both groups $(1.7 \%$ vs $1.6 \%)$. These results are in contrast to the meta-analysis
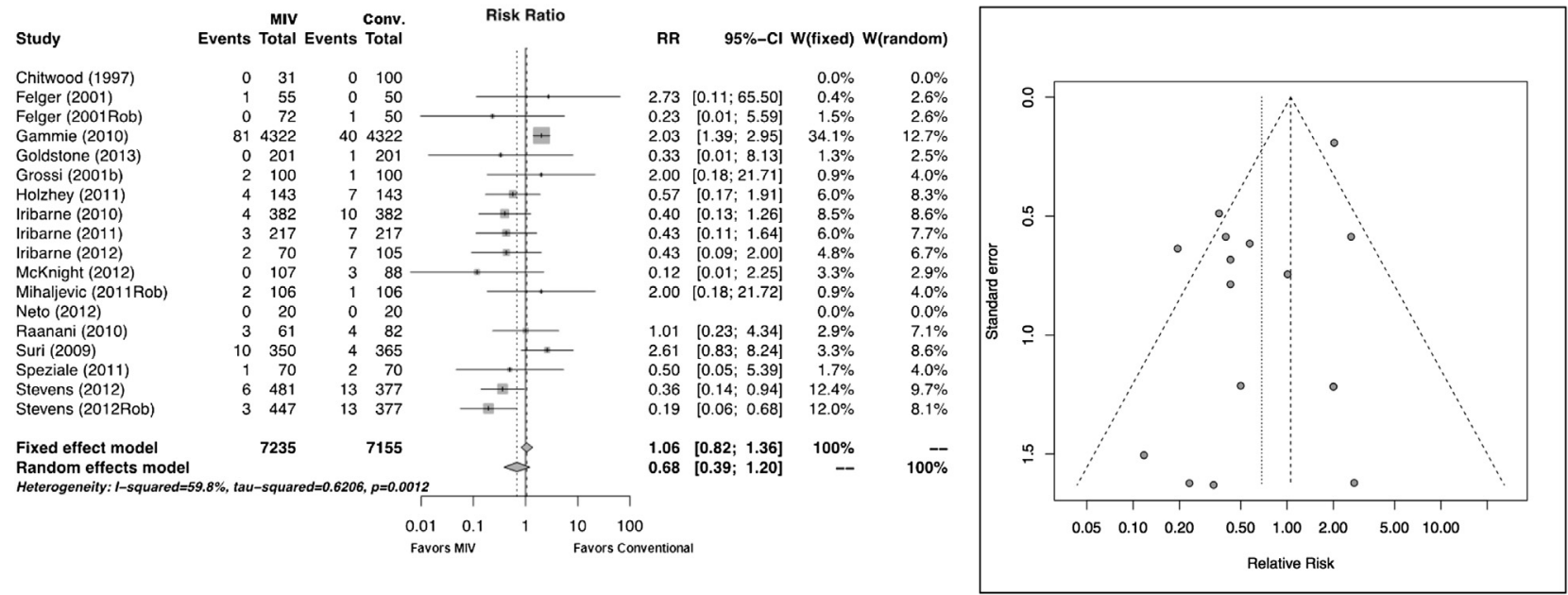

FIGURE 3. Forest and funnel plots for stroke rate. MIV, Minimally invasive; Conv, conventional; $R R$, risk ratio; $C I$, confidence interval; $W$, weight. 
TABLE 2. Secondary end points

\begin{tabular}{|c|c|c|c|c|c|c|c|c|}
\hline & $\mathbf{n}(\mathbf{N})$ & References & MIVS & CS & WMD or RR $(\mathbf{9 5} \% \mathbf{C I})$ & $\boldsymbol{P}$ & $\mathbf{I}^{2}(\%)$ & $\begin{array}{r}\text { FPA } \\
(P) \\
\end{array}$ \\
\hline $\begin{array}{l}\text { Procedure time, } \\
\text { minutes } \pm \mathrm{SD} \\
\text { (Figure E1) }\end{array}$ & $13(1469)$ & $6,8-12,16,21,33,40,43,44$ & $258 \pm 41.8$ & $210.7 \pm 34.4$ & $-51.6(26.2$ to 77$)$ & $<.001$ & 99 & $>.2$ \\
\hline $\begin{array}{l}\mathrm{CPB} \text { time, } \\
\quad \text { minutes } \pm \mathrm{SD} \\
\text { (Figure } \mathrm{E} 2 \text { ) }\end{array}$ & $28(5609)$ & $\begin{array}{l}5-7,8-12,15-18,21-24,26,30,33,34,36 \\
\quad 38,40,43-45\end{array}$ & $142.6 \pm 26.5$ & $107.7 \pm 25.2$ & $36.6(31.2$ to 41.9$)$ & $<.001$ & 99 & .08 \\
\hline $\begin{array}{l}\text { Crossclamp time, } \\
\text { minutes } \pm \mathrm{SD} \\
\text { (Figure E3) }\end{array}$ & $30(5953)$ & $\begin{array}{l}\text { 5-7,8-12,15-19,21-24,26,30,33-38,40, } \\
\quad 43-45\end{array}$ & $93.7 \pm 31.3$ & $74.2 \pm 27.5$ & 19.4 (13.7 to 25$)$ & $<.001$ & 99 & .13 \\
\hline $\begin{array}{l}\text { Blood drainage } \\
\text { volume, } \mathrm{mL} \pm \mathrm{SD} \\
\quad \text { (Figure } \mathrm{E} 4 \text { ) }\end{array}$ & $10(1322)$ & $5,7,9-12,16,40,43$ & $674 \pm 288$ & $775 \pm 292$ & $-142.1(-199.2$ to -85.1$)$ & $<.001$ & 96 & $>.2$ \\
\hline $\begin{array}{l}\text { Need for transfusion, } \\
\quad \% \text { (Figure E5) }\end{array}$ & $12(12,243)$ & $7,9,11,12,14,17,28,38,40,41$ & 37 & 45 & $0.67(0.51$ to 0.88$)$ & .004 & 93 & .19 \\
\hline $\begin{array}{l}\text { LOS ICU, } \\
\text { hours } \pm \text { SD } \\
\text { (Figure E6) }\end{array}$ & $16(1717)$ & $5-7,8,9,11,12,27,30,33,35,36,40,45$ & $44 \pm 30$ & $66 \pm 47$ & $-19.4(-27.1$ to -11.6$)$ & $<.001$ & 97 & $>.2$ \\
\hline $\begin{array}{l}\text { Respirator dependence, } \\
\text { hours } \pm \mathrm{SD} \\
\text { (Figure E7) }\end{array}$ & $16(2583)$ & $5,6,8,10,11,16,26,32,34,35,37,38,42,44$ & $12.3 \pm 11.2$ & $22.3 \pm 29.1$ & $-8.7(-14$ to -3.4$)$ & .001 & 99 & $>.2$ \\
\hline $\begin{array}{l}\text { LOS in hospital, } \\
\text { days } \pm \mathrm{SD} \\
\text { (Figure E8) }\end{array}$ & 27 (4948) & $5-8,10,11,16,17,21-24,27,30-38,40,45$ & $7.6 \pm 3.2$ & $9.4 \pm 3.4$ & $-2.0(-2.4$ to -1.5$)$ & $<.001$ & 99 & $>.2$ \\
\hline $\begin{array}{l}\text { Rethoracotomy, } \\
\text { \% (Figure E9) }\end{array}$ & $22(15,265)$ & $\begin{array}{l}7,9,11,12,14,17,21-24,26,28,32,34,35 \\
\quad 38,40,41,43,45\end{array}$ & 3.8 & 3.2 & 1.14 (1.0 to 1.3$)$ & .13 & 13 & .08 \\
\hline Aortic dissection, no. & $5(9823)$ & $14,18,21,32,38$ & 4 & 0 & $8.2(1.0$ to 65.2$)$ & .05 & 0 & - \\
\hline $\begin{array}{l}\text { New AF, \% } \\
\quad \text { (Figure E10) }\end{array}$ & $11(3646)$ & $6,7,16,17,21,28,30,33,38,41$ & 25 & 29 & $0.9(0.8$ to 1.0$)$ & .07 & 48 & $>.2$ \\
\hline $\begin{array}{l}\text { New renal insufficiency, } \\
\% \text { (Figure E11) }\end{array}$ & $11(11,346)$ & $7,11,14,17,21-24,32,40$ & 2.1 & 2.1 & $1.0(0.8$ to 1.3$)$ & 1 & 60 & .02 \\
\hline Costs (US\$) & $3(756)$ & $23-25$ & $35,135 \pm 1702$ & $42,742 \pm 2712$ & $-7594.3(-15,928$ to -739$)$ & .07 & 99 & - \\
\hline
\end{tabular}

$n$, Number of studies; $N$, total number of patients; $M I V S$, minimally invasive surgery, right lateral minithoracotomy; $C S$, conventional surgery, midline sternotomy; $W M D$, weighted mean difference; $R R$, risk ratio; $C I$, confidence interval; $I^{2}$, test of heterogeneity (when $\mathrm{I}^{2}$ was $>60 \%$, the random effects model was used, otherwise the fixed effects model was used); $F P A$, funnel plot asymmetry; $S D$, standard deviation; $C P B$, cardiopulmonary bypass; $L O S$, length of stay; $I C U$, intensive care unit; $A F$, atrial fibrillation.

by Cheng and colleagues. ${ }^{1}$ This can be explained by the number of newer studies, in which all reported stroke rates are in favor of MIVS. ${ }^{17,23,24,27,40,41}$ A reason could be that MIVS mitral valve surgery has evolved in terms of technology and surgeon experience, therefore challenges like deairing and worse exposure have been overcome. We also performed a subanalysis of studies that exclusively used endoaortic balloon occlusion or a transthoracic crossclamp in the MIVS group. Studies from centers where MIVS procedures are performed mainly with the use of the endoaortic balloon occlusion $^{5,6,9,15,16,18-20,26,28,29,32,33,35,36,38,42}$ reported stroke rates in favor of mitral valve CS. This is in contrast to studies from centers where the transthoracic aortic crossclamp was used predominantly. ${ }^{7,8,10-12,21-}$ $24,30,34,40,41,45$ These studies were obviously in favor of MIVS. From these data, it can be hypothesized that aortic balloon occlusion has an impact on neurologic outcome. In this context, it might be of great interest to conduct further studies that specifically investigate differences with regard to this particular outcome. There is strong asymmetry in the funnel plot for stroke indicating a study bias for this end point. Therefore, this result has to be viewed with caution.

We also assessed the impact of thoracic access with regard to blood loss, need for blood transfusion, and drainage volume. Blood drainage volume was significantly less (about $-142 \mathrm{~mL}$ ) in the MIVS group as might be assumed, with the argument that the smaller operative field leads to less need for blood transfusion. Accordingly, the need for blood transfusion was less in the MIVS group. The need for rethoracotomy because of bleeding complications did not differ significantly between both groups. Perioperative outcomes such as postoperative renal insufficiency, atrial fibrillation, and aortic dissections were also assessed. Our meta-analysis showed no difference between the groups for renal insufficiency or the rate of postoperative atrial fibrillation. The rate of aortic dissection was significantly 
higher in the MIVS group but the total number of dissections was low. In those publications reporting a higher incidence of aortic dissection in the MIVS group (1 was a propensity-matched study with a high number of patients ${ }^{14}$ ), no conclusive explanation could be offered for these findings. In all these studies except 1 , in which both aortic clamping techniques were used, endoaortic balloon occlusion was used. This might be a potential explanation but is totally hypothetical and must be confirmed or dismissed by further studies.

Another finding of our meta-analysis is that minimally invasive access is not associated with a lower number of mitral valve repairs. The number of mitral valve repairs compared with mitral valve replacements was higher in the MIVS group. Selection bias or different experience levels could explain this result.

Our meta-analysis has several limitations. First, the quality of all meta-analysis is limited by the studies that are included. For this meta-analysis, mainly retrospective studies were found. Only few were propensity matched, ${ }^{14,17,21,22,28,38}$ and thus similar to prospective randomized trials. The comparator in some studies was a historical group of patients treated via sternotomy ${ }^{11,33}$ because thoracotomy has become the standard access and thus no actual control group treated through a sternotomy was available. It also cannot be excluded that there was significant data overlap for some studies, with data from overlapping patient cohorts reported at different points of time; for example, the 3 studies from Iribarne and colleagues. $^{22-24}$ Also, reporting from outcome data varied throughout the studies. It also cannot be excluded that patients who were included in the Society of Thoracic Surgeons database analysis by Gammie and colleagues ${ }^{14}$ are the same as those included in smaller studies in the United States. This has been broadly discussed in the meta-analysis by Cheng and colleagues. ${ }^{1}$ The authors concluded that this did not have any significant impact on the conclusion because of the large weight of the study by Gammie and colleagues ${ }^{14}$ compared with the other studies. The newer studies that are included in this meta-analysis are not included in any larger database analysis. Another factor in every study that compares different techniques and can bias the results, is that different techniques are more likely to be performed by different surgeons and not by 1 single surgeon. But this is not described in most of the studies included. We also did not address the underlying cause of the mitral valve disease. A recent meta-analysis ${ }^{46}$ did so comparing lateral minithoracotomy and median sternotomy for mitral valve surgery in patients with degenerative mitral valve disease. The results are in accordance with ours; no significant differences in clinical end points such as mortality, cerebrovascular accidents, and others were found. Because of these limitations, meta-analyses cannot replace prospective randomized trials.

In conclusion, this meta-analysis showed that perioperative outcome is similar for minimally invasive mitral valve surgery performed via a right lateral thoracotomy and conventional mitral valve surgery performed via median sternotomy. In contrast to the recent meta-analysis by Cheng and colleagues, ${ }^{1}$ we did not find an increase in stroke rate in the MIVS group. Mitral valve surgery via a right lateral minithoracotomy seems to be favorable with regard to resource-related outcomes.

\section{References}

1. Cheng DCH, Martin J, Lal A, Diegeler A, Folliguet TA, Nifong LW, et al. Minimally invasive versus conventional open mitral valve surgery: a meta-analysis and systematic review. Innovations (Phila). 2011;6:84-103.

2. Modi P, Hassan A, Chitwood WR. Minimally invasive mitral valve surgery: a systematic review and meta-analysis. Eur J Cardiothorac Surg. 2008;34: 943-52.

3. Stroup DF, Berlin JA, Morton SC, Olkin I, Williamson GD, Rennie D, et al. Meta-analysis of observational studies in epidemiology: a proposal for reporting. Meta-analysis Of Observational Studies in Epidemiology (MOOSE) group. JAMA. 2000;283:2008-12.

4. Moher D, Liberati A, Tetzlaff J, Altman DG, Grouppara TP. Preferred reporting items for systematic reviews and meta-analyses: the PRISMA statement. J Clin Epidemiol. 2009;62:1006-12.

5. Antonic M, Gersak B. Renal function after port access and median sternotomy mitral valve surgery. Heart Surg Forum. 2007;10:E401-7.

6. Chaney MA, Durazo-Arvizu RA, Fluder EM, Sawicki KJ, Nikolov MP, Blakeman BP, et al. Port-access minimally invasive cardiac surgery increases surgical complexity, increases operating room time, and facilitates early postoperative hospital discharge. Anesthesiology. 2000;92:1637-45.

7. Chitwood WR, Wixon CL, Elbeery JR, Moran JF, Chapman WHH, Lust RM Video- assisted minimally invasive mitral valve surgery. J Thorac Cardiovasc Surg. 1997; 114:773-80.

8. de Vaumas C, Philip I, Daccache G, Depoix J-P, Lecharny J-B, Enguerand D, et al. Comparison of minithoracotomy and conventional sternotomy approaches for valve surgery. J Cardiothorac Vasc Anesth. 2003;17:325-8.

9. Dogan S, Aybek T, Risteski PS, Detho F, Rapp A, Wimmer-Greinecker G, et al. Minimally invasive port access versus conventional mitral valve surgery: prospective randomized study. Ann Thorac Surg. 2005;79:492-8.

10. El-Fiky MM, El-Sayegh T, El-Beishry AS, Aziz MA, Enein HA, Waheid S, et al Limited right anterolateral thoracotomy for mitral valve surgery. Eur J Cardiothorac Surg. 2000;17:710-3.

11. Felger JE, Chitwood WR, Nifong LW, Holbert D. Evolution of mitral valve surgery: toward a totally endoscopic approach. Ann Thorac Surg. 2001;72: 1203-8.

12. Folliguet T, Vanhuyse F, Constantino X, Realli M, Laborde F. Mitral valve repair robotic versus sternotomy. Eur J Cardiothorac Surg. 2006;29:362-6.

13. Galloway AC, Schwartz CF, Ribakove GH, Crooke GA, Gogoladze G, Ursomanno P, et al. A decade of minimally invasive mitral repair: Long-term outcomes. Ann Thorac Surg. 2009;88:1180-4.

14. Gammie JS, Zhao Y, Peterson ED, O’Brien SM, Rankin JS, Griffith BP. Less-invasive mitral valve operations: trends and outcomes from the Society of Thoracic Surgeons adult cardiac surgery database. Ann Thorac Surg. 2010;90: 1401-8.

15. Gersak B, Sostaric M, Kalisnik JM, Blumauer R. The preferable use of port access surgical technique for right and left atrial procedures. Heart Surg Forum. 2005;8:E354-63.

16. Glower DD, Landolfo KP, Clements F, Debruijn NP, Stafford-Smith M, Smith PK, et al. Mitral valve operation via port access versus median sternotomy Eur J Cardiothorac Surg. 1998;14(Suppl):143-7.

17. Goldstone AB, Atluri P, Szeto W, Trubelja A, Howard JL, MacArthur JW, et al Minimally invasive approach provides at least equivalent results for surgical correction of mitral regurgitation: a propensity-matched comparison. J Thorac Cardiovasc Surg. 2013;145:748-56. 
18. Grossi EA, LaPietra A, Ribakove GH, Delianides J, Esposito R, Culliford AT, et al. Minimally invasive versus sternotomy approaches for mitral reconstruction: comparison of intermediate-term results. J Thorac Cardiovasc Surg. 2001;121: 708-13.

19. Grossi EA, Galloway AC, Ribakove GH, Zakow PK, Derivaux CC, Baumann FG, et al. Impact of minimally invasive valvular heart surgery: a case-control study. Ann Thorac Surg. 2001;71:807-10.

20. Grossi EA, Loulmet DF, Schwartz CF, Solomon B, Dellis SL, Culliford AT, et al. Minimally invasive valve surgery with antegrade perfusion strategy is not associated with increased neurologic complications. Ann Thorac Surg. 2011; 92:1346-50.

21. Holzhey DM, Shi W, Borger MA, Seeburger J, Garbade J, Pfannmüller B, et al. Minimally invasive versus sternotomy approach for mitral valve surgery in patients greater than 70 years old: a propensity-matched comparison. Ann Thorac Surg. 2011;91:401-5.

22. Iribarne A, Russo MJ, Easterwood R, Hong KN, Yang J, Cheema FH, et al. Minimally invasive versus sternotomy approach for mitral valve surgery: a propensity analysis. Ann Thorac Surg. 2010;90:1471-8.

23. Iribarne A, Easterwood R, Russo MJ, Wang YC, Yang J, Hong KN, et al. A minimally invasive approach is more cost-effective than a traditional sternotomy approach for mitral valve surgery. J Thorac Cardiovasc Surg. 2011;142:1507-14.

24. Iribarne A, Easterwood R, Russo MJ, Chan EY, Smith CR, Argenziano M. Comparative effectiveness of minimally invasive versus traditional sternotomy mitral valve surgery in elderly patients. J Thorac Cardiovasc Surg. 2012;143: S86-90.

25. Kam JK, Cooray SD, Smith JA. A cost-analysis study of robotic versus conventional mitral valve repair. Heart Lung Circ. 2010;19:413-8.

26. McCreath BJ, Swaminathan M, Booth JV, Phillips-Bute B, Chew STH, Glower DD, et al. Mitral valve surgery and acute renal injury: port access versus median sternotomy. Ann Thorac Surg. 2003;75:812-9.

27. McKnight CLC, Davis BB, Wright CC, Blackhurst DD, Bolton WW. Minimally invasive mitral valve surgery: smaller incisions, better outcomes? Am Surg. 2012; 78:E370-2.

28. Mihaljevic T, Jarrett CM, Gillinov AM, Williams SJ, DeVilliers PA, Stewart WJ, et al. Robotic repair of posterior mitral valve prolapse versus conventional approaches: potential realized. J Thorac Cardiovasc Surg. 2011; 141:72-4.

29. Mohr FW, Falk V, Diegeler A, Walther T, von Son JAM, Autschbach R, et al. Minimally invasive port-access mitral valve surgery. J Thorac Cardiovasc Surg. 1998;115:567-74.

30. Neto JV, Melo E, Fernandes J, Gomes R, Freitas C, Machado J, et al. Mitral valve and atrial septal defect surgery: minimally invasive or sternotomy approach. Arq Bras Cardiol. 2012;99:681-7.

31. Nikolic A, Huskic R, Jovovic L, Radomir B, Cirkovic M, Bojic M. Our experience with minimally invasive surgery. Cor Europaeum. 2000;8:57.
32. Raanani E, Spiegelstein D, Sternik L, Reisman S, Moshkovitz Y, Smolinsky AK et al. Quality of mitral valve repair: median sternotomy versus port-access approach. J Thorac Cardiovasc Surg. 2010;140:86-90.

33. Reichenspurner H, Boehm DH, Gulbins H, Schulze C, Wildhirt S, Welz A, et al. Three-dimensional video and robot-assisted port-access mitral valve operation. Ann Thorac Surg. 2000;69:1176-81.

34. Ruttmann E, Laufer G, Müller LC. Etablierung eines Programms für minimal invasive Mitraklappenoperationen an der Univ. Klinik Innsbruck [Establishmen of a program for minimally invasive mitral valve surgery at the Univ. Clinic Innsbruck]. Eur Surg. 2006;38:320-5 [in German].

35. Ryan WH, Brinkman WT, Dewey TM, Mack MJ, Prince SL, Herbert MA. Mitral valve surgery: comparison of outcomes in matched sternotomy and port access groups. J Heart Valve Dis. 2009;19:51-9.

36. Schneider F, Onnasch JF, Falk V, Walther T, Autschbach R, Mohr FW. Cerebra microemboli during minimally invasive and conventional mitral valve operations. Ann Thorac Surg. 2000;70:1094-7.

37. Srivastava AK, Garg SK, Ganjoo AK. Approach for primary mitral valve surgery: right anterolateral thoracotomy or median sternotomy. J Heart Valve Dis. 1998; 370-5.

38. Suri RM, Schaff HV, Meyer SR, Hargrove WC. Thoracoscopic versus open mitral valve repair: a propensity score analysis of early outcomes. Ann Thorac Surg. 2009;88:1185-90.

39. Suri RM, Antiel RM, Burkhart HM, Huebner M, Li Z, Eton DT, et al. Quality of life after early mitral valve repair using conventional and robotic approaches. Ann Thorac Surg. 2012;93:761-9.

40. Speziale G, Nasso G, Esposito G, Conte M, Greco E, Fattouch K, et al. Results of mitral valve repair for Barlow disease (bileaflet prolapse) via right minithoracotomy versus conventional median sternotomy: a randomized trial. J Thorac Cardiovasc Surg. 2011;142:77-83.

41. Stevens LM, Rodriguez E, Lehr EJ, Kindell LC, Nifong LW, Ferguson TB, et al Impact of timing and surgical approach on outcomes after mitral valve regurgitation operations. Ann Thorac Surg. 2012;93:1462-8.

42. Walther T, Falk V, Metz S, Diegeler A, Battellini R, Autschbach R, et al. Pain and quality of life after minimally invasive versus conventional cardiac surgery. Ann Thorac Surg. 1999;67:1643-7.

43. Wang D, Wang Q, Yang X, Wu Q, Li Q. Mitral valve replacement through a minimal right vertical infra-axillary thoracotomy versus standard median sternotomy. Ann Thorac Surg. 2009;87:704-8.

44. Wei LL, Shen J-QJ, Wang C-SC, Xia L-ML, Yang Z-HZ, Liu HH, et al. Repair of posterior mitral valve prolapsed: comparative study of three different approaches. Zhonghua Wai Ke Za Zhi. 2012;50:637-41.

45. Woo YJ, Nacke EA. Robotic minimally invasive mitral valve reconstruction yields less blood product transfusion and shorter length of stay. Surgery. 2006;140:263-7.

46. Cao C, Gupta S, Chandrakumar D, Nienaber TA, Indraratna P, Ang SC, et al. A meta-analysis of minimally invasive versus conventional mitral valve repair for patients with degenerative mitral disease. Ann Cardiothorac Surg. 2013;2:693-703. 

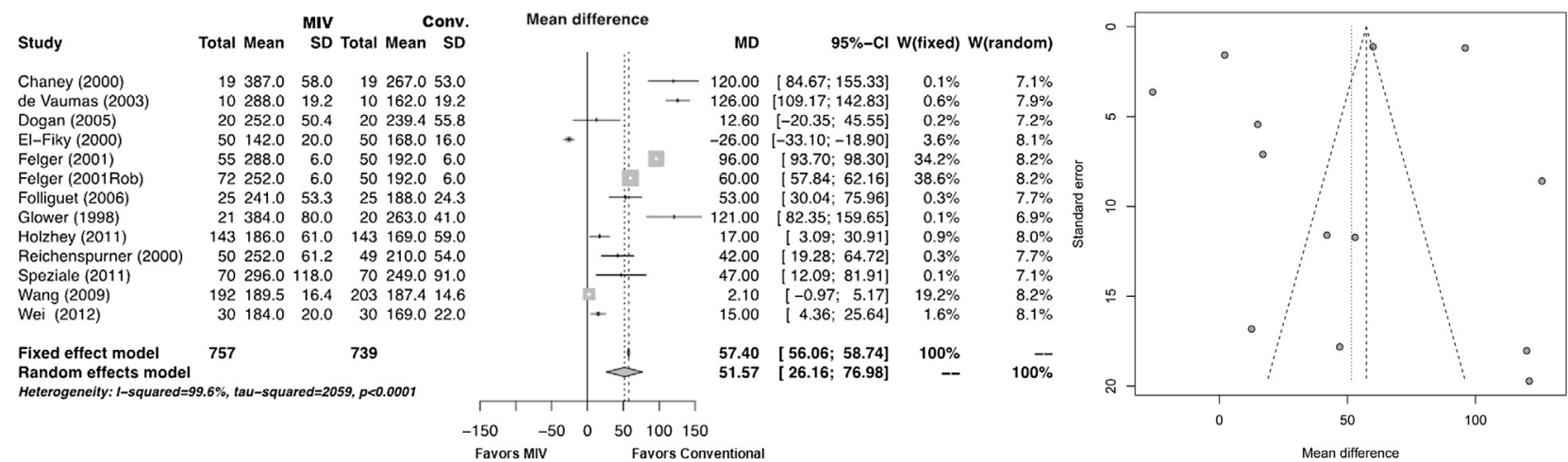

FIGURE E1. Forest and funnel plots for procedure time in minutes. MIV, Minimally invasive; Conv, conventional; $S D$, standard deviation; $M D$, mean difference; $C I$, confidence interval; $W$, weight.
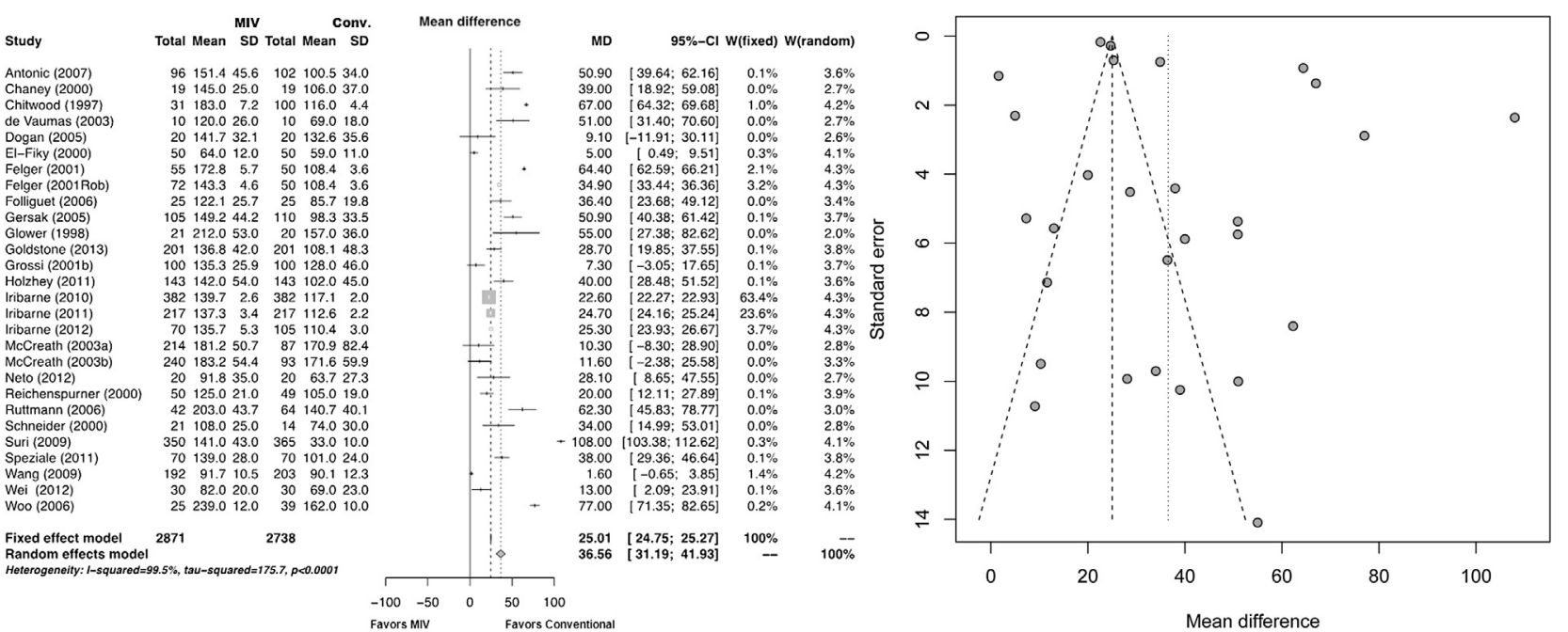

FIGURE E2. Forest and funnel plots for cardiopulmonary bypass time in minutes. MIV, Minimally invasive; Conv, conventional; SD, standard deviation; $M D$, mean difference; $C I$, confidence interval; $W$, weight.
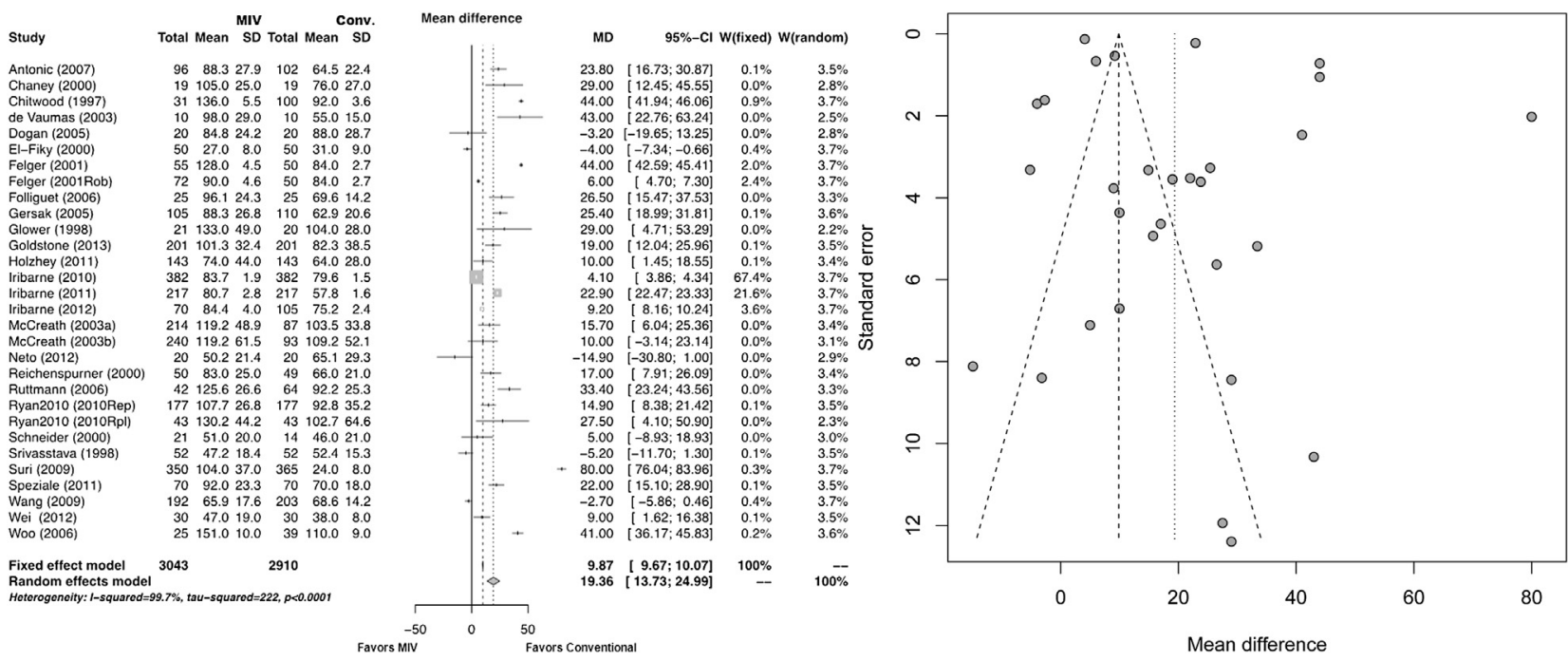

FIGURE E3. Forest and funnels plot for crossclamp time in minutes. MIV, Minimally invasive; Conv, conventional; $S D$, standard deviation; $M D$, mean difference; $C I$, confidence interval; $W$, weight. 


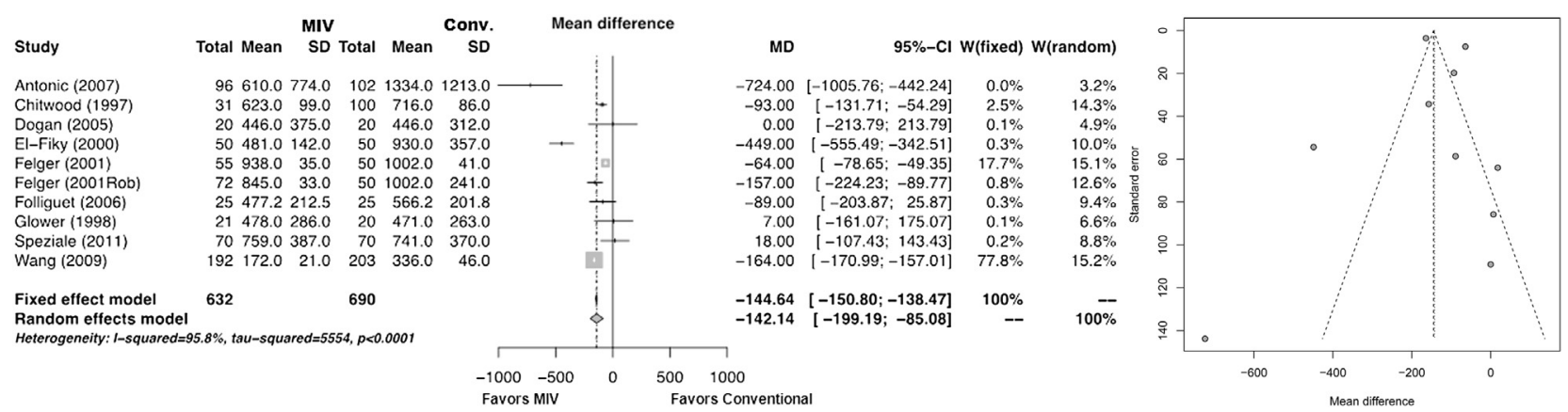

FIGURE E4. Forest and funnel plots for blood drainage volume in milliliters. MIV, Minimally invasive; Conv, conventional; $S D$, standard deviation; $M D$, mean difference; $C I$, confidence interval; $W$, weight.
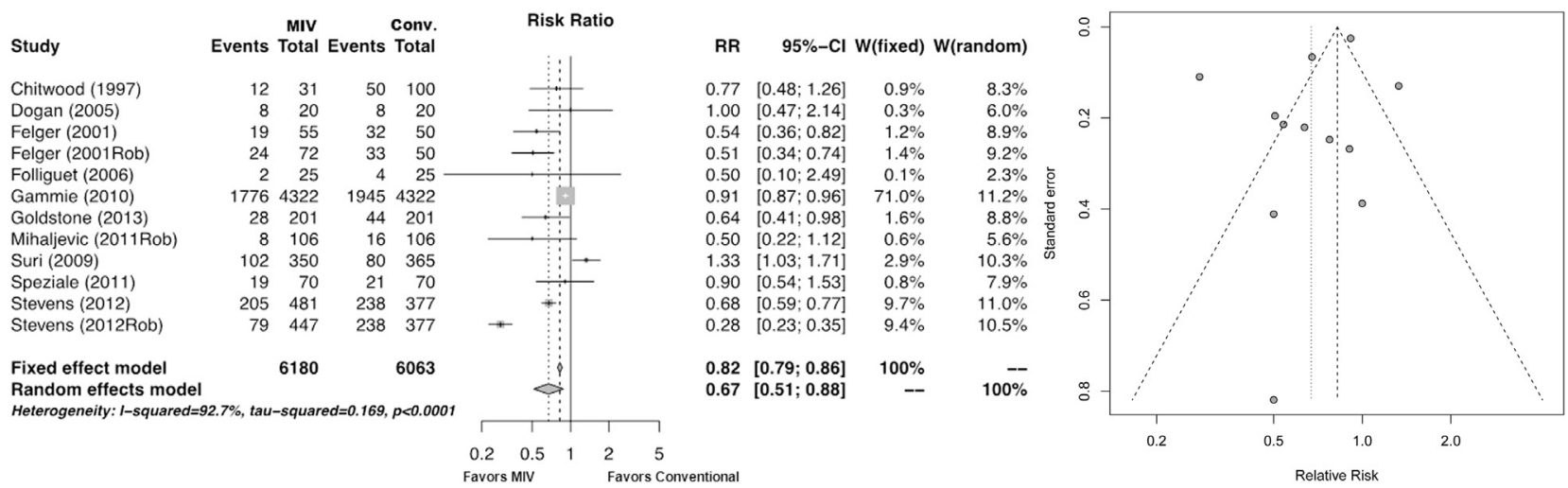

FIGURE E5. Forest and funnel plots for the number of patients who needed blood transfusion. MIV, Minimally invasive; Conv, conventional; $R R$, risk ratio; $C I$, confidence interval; $W$, weight.
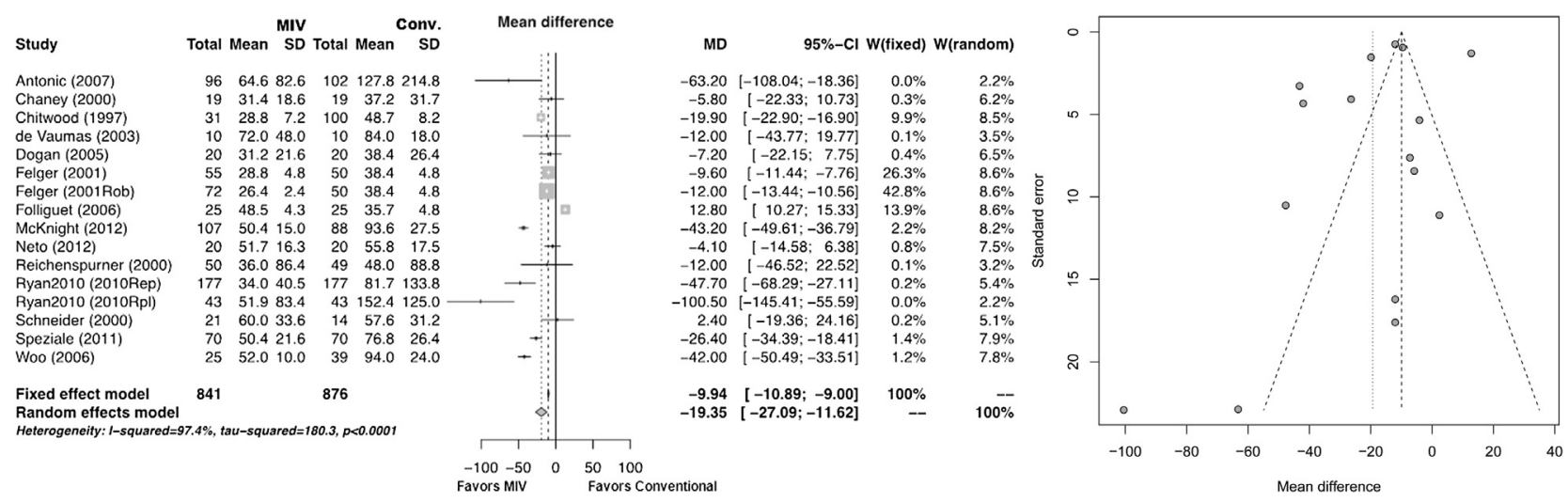

FIGURE E6. Forest and funnel plots for length of stay in the intensive care unit in hours. MIV, Minimally invasive; Conv, conventional; SD, standard deviation; $M D$, mean difference; $C I$, confidence interval; $W$, weight. 

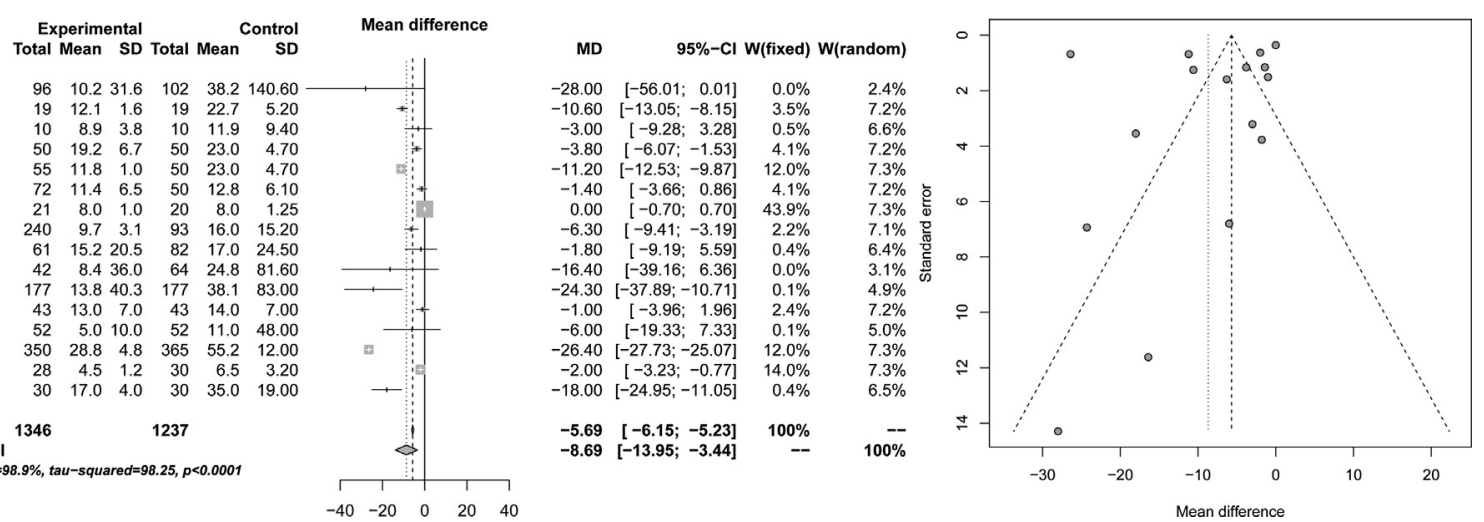

FIGURE E7. Forest and funnel plots for length of respirator dependence time in hours. MIV, Minimally invasive; Conv, conventional; SD, standard deviation; $M D$, mean difference; $C I$, confidence interval; $W$, weight.
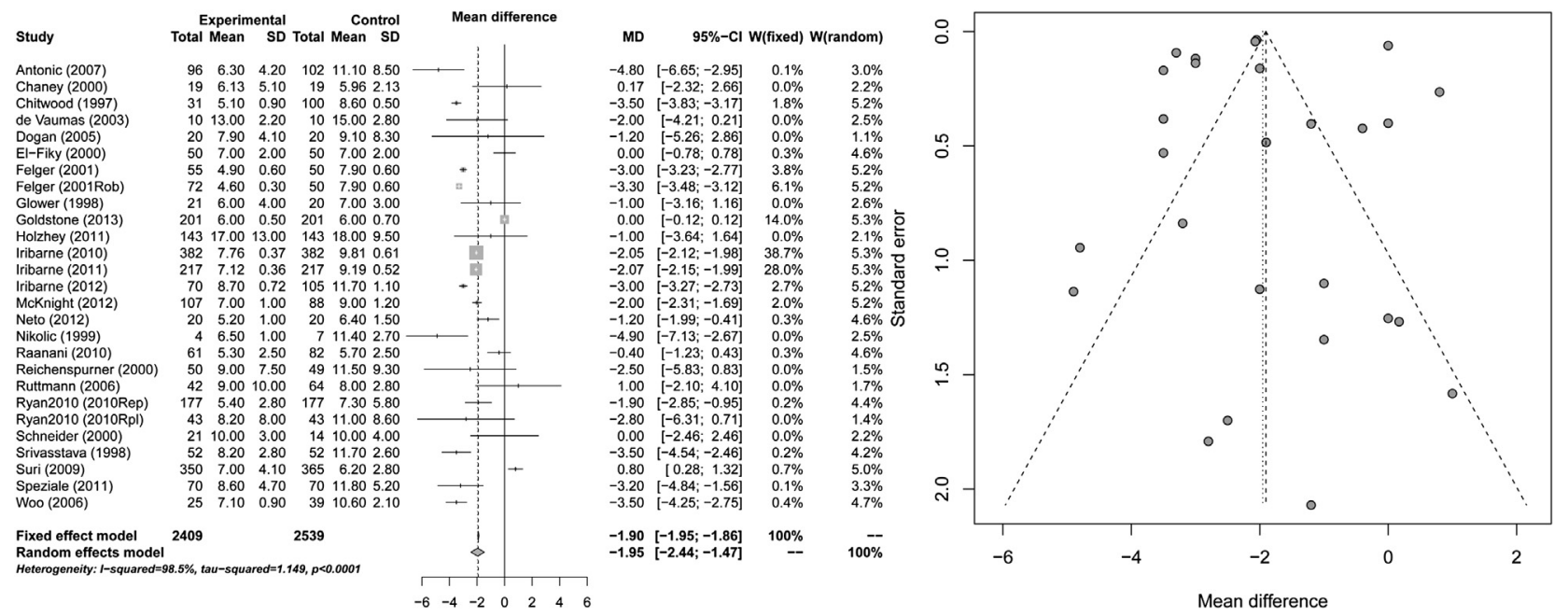

FIGURE E8. Forest and funnel plots for length of hospital stay in days. MIV, Minimally invasive; Conv, conventional; $S D$, standard deviation; $M D$, mean difference; $C I$, confidence interval; $W$, weight.
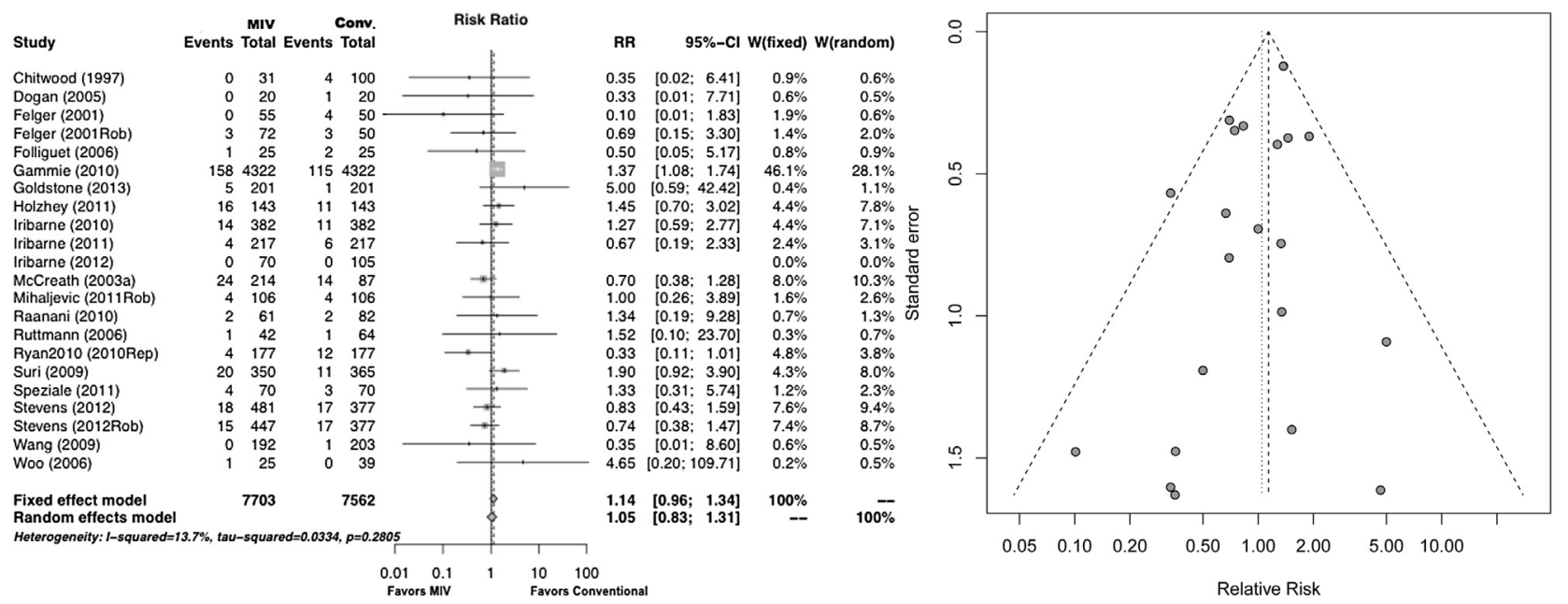

FIGURE E9. Forest and funnel plots for patients who needed a rethoracotomy for bleeding complications. MIV, Minimally invasive; Conv, conventional; $R R$, risk ratio; $C I$, confidence interval; $W$, weight. 


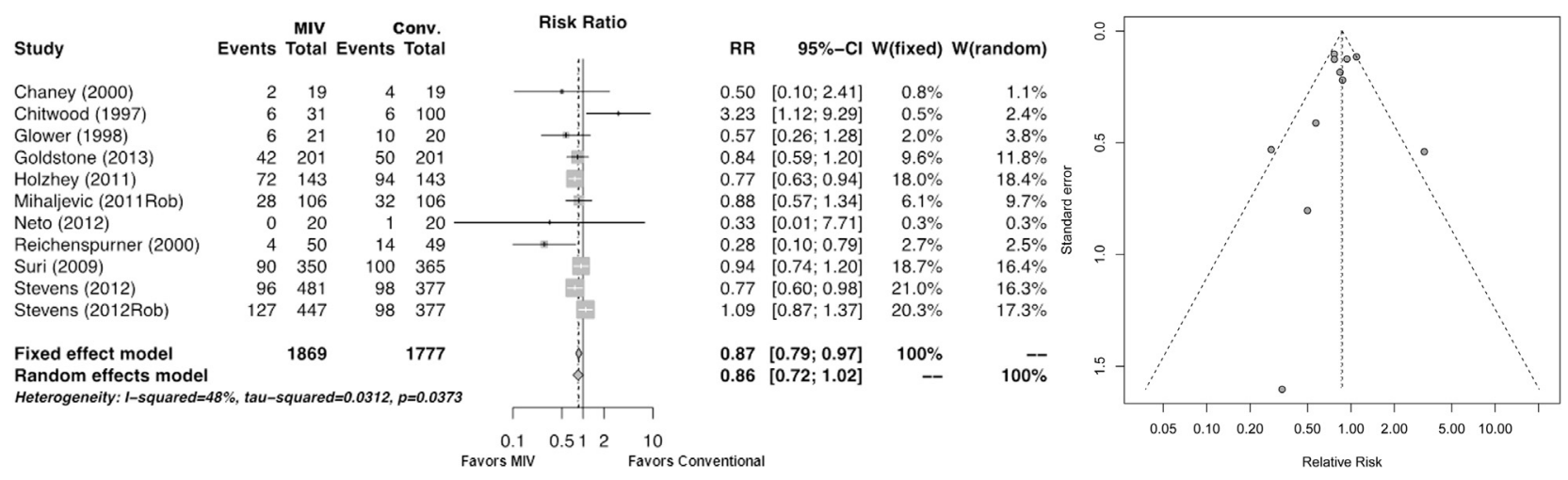

FIGURE E10. Forest and funnel plots for new onset of atrial fibrillation. $M I V$, Minimally invasive; Conv, conventional; $R R$, risk ratio; $C I$, confidence interval; $W$, weight.

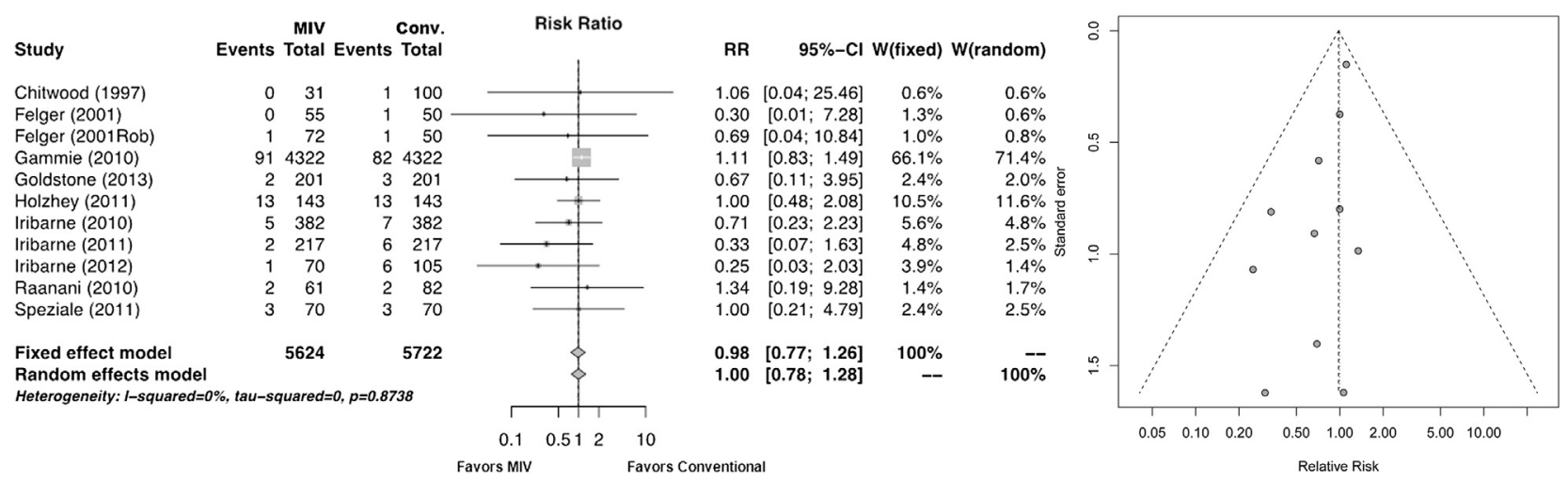

FIGURE E11. Forest and funnel plots for new postoperative renal failure. $M I V$, Minimally invasive; Conv, conventional; $R R$, risk ratio; $C I$, confidence interval; $W$, weight. 